\title{
Advanced Glycation End Products Induce Obesity and Hepatosteatosis in CD-1 Wild-Type Mice
}

\author{
Wael N. Sayej, ${ }^{1,2}$ Paul R. Knight III, ${ }^{3,4,5}$ Weidun Alan Guo, ${ }^{6}$ \\ Barbara Mullan, ${ }^{3,7}$ Patricia J. Ohtake, ${ }^{8}$ Bruce A. Davidson, ${ }^{3,4,7}$ Abdur Khan, \\ Robert D. Baker, ${ }^{9}$ and Susan S. Baker ${ }^{10}$ \\ ${ }^{1}$ Digestive Diseases, Hepatology and Nutrition Center, Connecticut Children's Medical Center, Hartford, CT 06106, USA \\ ${ }^{2}$ University of Connecticut School of Medicine, Farmington, CT 06032, USA \\ ${ }^{3}$ Department of Anesthesiology, School of Medicine and Biomedical Sciences, State University of New York at Buffalo, \\ Buffalo, NY 14214, USA \\ ${ }^{4}$ Veterans Administration Western New York Healthcare System, State University of New York at Buffalo, Buffalo, NY 14215, USA \\ ${ }^{5}$ Department of Microbiology and Immunology, School of Medicine and Biomedical Sciences, State University of New York at Buffalo, \\ Buffalo, NY 14214, USA \\ ${ }^{6}$ Department of Surgery, University at Buffalo-SUNY School of Medicine, Buffalo, NY 14214, USA \\ ${ }^{7}$ Departments of Pathology and Anatomical Sciences, School of Medicine and Biomedical Sciences, Buffalo, NY 14228, USA \\ ${ }^{8}$ Department of Rehabilitation Science, University at Buffalo-SUNY School of Medicine, Buffalo, NY 14214, USA \\ ${ }^{9}$ Department of Pediatric Pathology, Women \& Children's Hospital of Buffalo, Buffalo, NY 14203, USA \\ ${ }^{10}$ Digestive Diseases and Nutrition Center, Division of Pediatric Gastroenterology, Women \& Children's Hospital of Buffalo, \\ Buffalo, NY 14222, USA
}

Correspondence should be addressed to Wael N. Sayej; wsayejmd@yahoo.com

Received 1 December 2015; Accepted 10 January 2016

Academic Editor: Yanwen Wang

Copyright (C) 2016 Wael N. Sayej et al. This is an open access article distributed under the Creative Commons Attribution License, which permits unrestricted use, distribution, and reproduction in any medium, provided the original work is properly cited.

AGEs are a heterogeneous group of molecules formed from the nonenzymatic reaction of reducing sugars with free amino groups of proteins, lipids, and/or nucleic acids. AGEs have been shown to play a role in various conditions including cardiovascular disease and diabetes. In this study, we hypothesized that AGEs play a role in the "multiple hit hypothesis" of nonalcoholic fatty liver disease (NAFLD) and contribute to the pathogenesis of hepatosteatosis. We measured the effects of various mouse chows containing high or low AGE in the presence of high or low fat content on mouse weight and epididymal fat pads. We also measured the effects of these chows on the inflammatory response by measuring cytokine levels and myeloperoxidase activity levels on liver supernatants. We observed significant differences in weight gain and epididymal fat pad weights in the high AGE-high fat (HAGE-HF) versus the other groups. Leptin, TNF- $\alpha$, IL-6, and myeloperoxidase (MPO) levels were significantly higher in the HAGE-HF group. We conclude that a diet containing high AGEs in the presence of high fat induces weight gain and hepatosteatosis in CD-1 mice. This may represent a model to study the role of AGEs in the pathogenesis of hepatosteatosis and steatohepatitis.

\section{Introduction}

Nonalcoholic fatty liver disease (NAFLD) is defined histologically as a spectrum of liver diseases, ranging from hepatosteatosis to nonalcoholic steatohepatitis (NASH) and cirrhosis [1-3]. There is tremendous interindividual variability in the tendency to develop cirrhosis, the stage of NAFLD that is associated with the greatest liver-related morbidity and mortality [4]. The variable progression of NAFLD may be explained by the "multiple hit" hypothesis $[3,5,6]$. According to this hypothesis, a primary insult ("1st hit"), such as insulin resistance (IR), which may be primary or secondary to obesity [7-10], causes normal livers to accumulate fat $[4,11]$. Fatty livers are unusually vulnerable to damage from various 
secondary insults and NASH develops when fatty livers experience a "2nd hit," such as exposure to intestinal bacterial products and/or rapid mobilization of fatty acids from visceral (central) fat that induces inflammatory cytokines, which cause oxidative stress and further dysfunction $[12,13]$. The liver is well known as a target organ and an important site for clearance and catabolism of macromolecules such as advanced glycation end products (AGEs) [14, 15]. AGEs have been shown to be elevated in patients with NASH [16-18].

AGEs are a heterogeneous group of molecules formed from the nonenzymatic reaction of reducing sugars with free amino groups of proteins, lipids, and/or nucleic acids. AGEs may be formed exogenously as a result of a chemical reaction by heating reducing sugars in the presence of fats or amino group containing compounds (Maillard reaction) and are commonly found in cooked Western Diets [19]. Additionally, tobacco smoke has been shown to be a source of toxic reactive AGEs [20] and tobacco-derived AGEs have been shown to increase risk for developing cancers and cardiovascular disease in former smokers [21]. AGEs are also produced endogenously during normal metabolism, aging [22-26] or due to hyperglycemia (e.g., diabetic patients) $[27,28]$. Foods may contain up to 200 times the initial AGE content after cooking [29]. Processed foods have also been shown to be very high in AGEs and pose a significant problem in the Western world [19]. One of the most wellknown AGEs, discovered in the 1960s, is hemoglobin Alc, which is also known as an Amadori product. Other wellknown and investigated AGEs include $N^{\varepsilon}$-carboxymethyllysine (CML) [28, 30], pentosidine [31], methylglyoxal [32], and imidazolone [33-35]. CML has been shown to correlate with severity in patients with chronic liver disease (fibrosis and cirrhosis) [36].

The interaction of AGEs with their cell surface receptor (RAGE) has been shown to play a role in the pathogenesis of various devastating disorders [37] such as cancers [21, 38-42], Alzheimer's disease [43, 44], insulin resistance [45], diabetes and its complications including micro- and macrovascular disease, retinopathy [46], neuropathy, and nephropathy [47, 48], liver cirrhosis $[49,50]$, and nonalcoholic steatohepatitis (NASH) $[16,17,51]$.

The detrimental effects of high fat content in the diet on obesity, diabetes, and cardiovascular disease are well known [52]. The detrimental effects of high levels of AGEs are also well studied in various diseases. The effects of AGEs on livers have only recently become a topic of discussion and research. Leung et al., utilizing an experimental mouse model, recently demonstrated that high dietary AGEs increase hepatic AGE content and exacerbate liver injury, inflammation, and liver fibrosis via oxidative stress and receptor for advanced glycation end product- (RAGE-) dependent profibrotic effects of AGEs on activated hepatic stellate cells [53]. We hypothesized that AGEs play an important role in the "multiple hit hypothesis" and thus the pathogenesis of hepatosteatosis and steatohepatitis. We also speculate that the presence of additional stressors (i.e., fat) is needed in the presence of high AGEs to cause significant hepatosteatosis and steatohepatitis.

Furthermore, there are a variety of inflammatory cytokines derived from adipose tissue, such as leptin, interleukin-6 (IL-6), and TNF-alpha (TNF- $\alpha$ ). These cytokines have been found to be increased in obesity and may contribute to inflammation and hepatosteatosis. Myeloperoxidase (MPO) has been used to examine neutrophil infiltration and is regarded as a sign of tissue inflammation. The role that cytokines, AGEs, or their combination plays in the pathogenesis of NASH is unknown. Further, there is no data on the activity of MPO in NAFLD or how MPO might change with the development of disease. Based on this knowledge, we propose that AGEs play an important role in this "multiple hit" process and thus the pathogenesis of NAFLD, along with additional stressor such as fat and inflammatory cytokines.

\section{Materials and Methods}

2.1. The Animals. Four-week-old male CD-1 wild-type outbred mice purchased from Charles River Laboratories (Wilmington, MA) were used for this study. The mice were housed at an animal facility at the Buffalo Veterans Affairs Medical Center. All procedures were approved by the Institutional Animal Care and Use Committee at the Buffalo Veterans Affairs Hospital and complied with all State, Federal, and National Institutes of Health regulations.

2.2. The Diets. The mice were fed a standard rodent diet, Purina 5L79 (LabDiet ${ }^{\ominus}$, St. Louis, MO) for the 1st 4 weeks of life. Once in our animal facilities (at 4 weeks of age), the mice were fed ad libitum two different rodent chows from Bio-Serv ${ }^{\bullet}$ (Frenchtown, NJ, USA) and Harlan ${ }^{\circledR}$ Laboratories (Madison, WI, USA) until sacrifice. The first diet from BioServ, a semipurified standard diet, AIN-93G rodent diet (Stk\# F3542), was processed with $100^{\circ} \mathrm{C}$ heating for $20-60$ seconds. To create the high AGE diet, the chow was heated for additional 30 minutes at $125^{\circ} \mathrm{C}$. The second diet from Harlan Laboratories, also a standard rodent diet (Stk\# Tek 70001.15), was processed with heating at $60-80^{\circ} \mathrm{C}$ for $20-30$ seconds and additional 5 seconds at $65-85^{\circ} \mathrm{C}$. To create the high AGE diet, the chow was heated for additional 30 minutes at $125^{\circ} \mathrm{C}$. Table 1 summarizes the macro- and micronutrients of each of the diets as well as the AGE levels in each of the diets. Figure 1 is a flow diagram of the mouse groups based on diet (chow) given.

The groups and diets were designated the following names: groups 1 and 5 received Bio-Serv's high AGE/high fat (HAGE-HF), groups 2 and 6 received Bio-Serv's low AGE/high fat (LAGE-HF), groups 3 and 7 received Harlan's high AGE/low fat (HAGE-LF), and groups 4 and 8 received Harlan's low AGE/low fat (LAGE-LF) chow. We were not sure if 4 weeks was enough time for the diets to change the phenotype and therefore, we decided to give the diets for 4 weeks and 6 weeks to determine if that made a difference in the phenotypes. Additionally, we wanted to see if there was progression of the inflammation from 4 to 6 weeks. Groups 1-4 received the diets for a total of 4 weeks and sacrifice was at 8 weeks \pm 2 days of age. Groups 5-8 received the diets for a total of 6 weeks and sacrifice was at 10 weeks \pm 2 days of age. The mice were fed ad libitum. The mice were weighed at time 
TABLE 1: Dietary macro- and micronutrients and AGE levels.

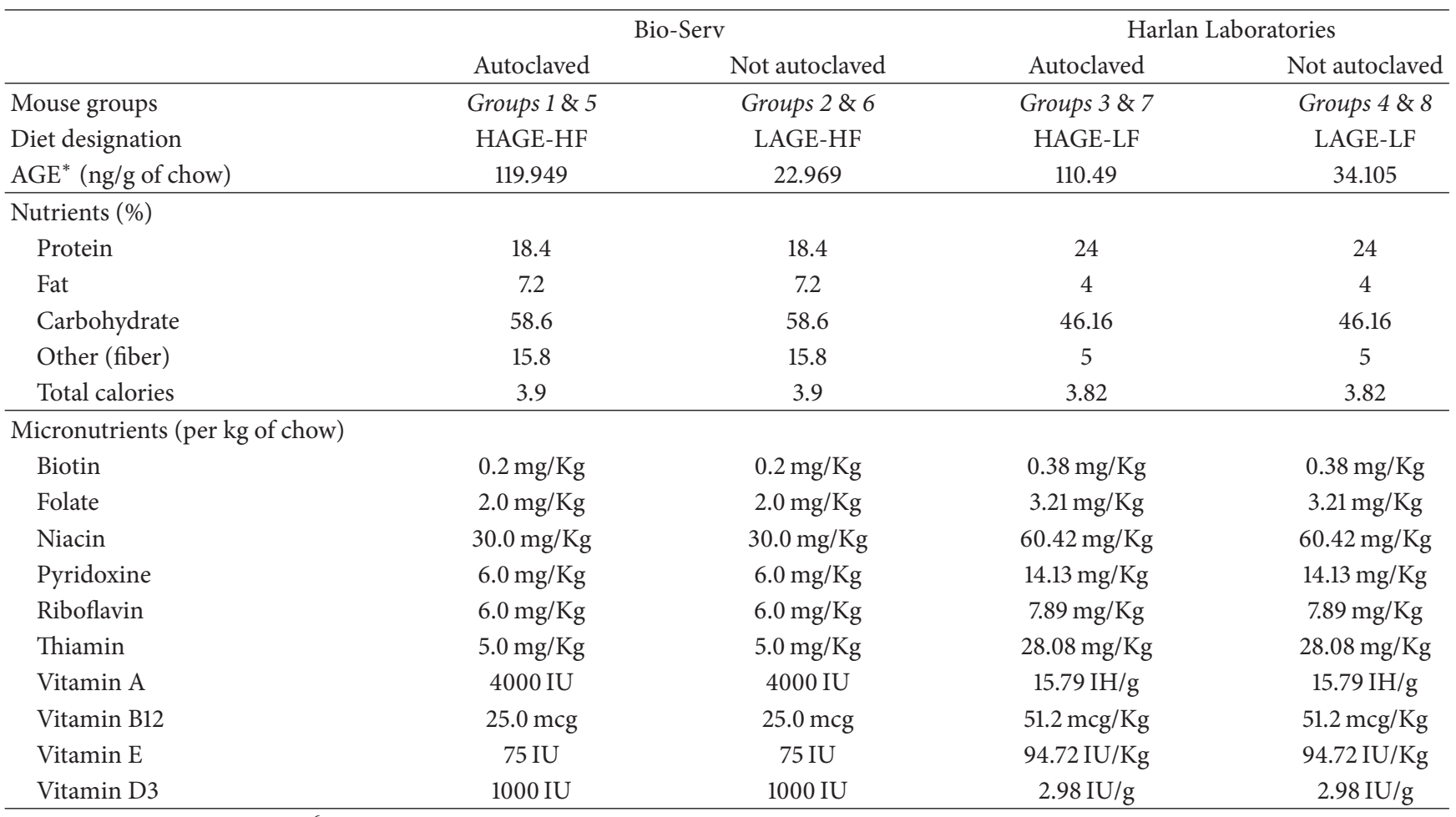

*AGE: measured using CML- ( $N^{6}$-carboxymethyl-lysine-) sensitive ELISA.
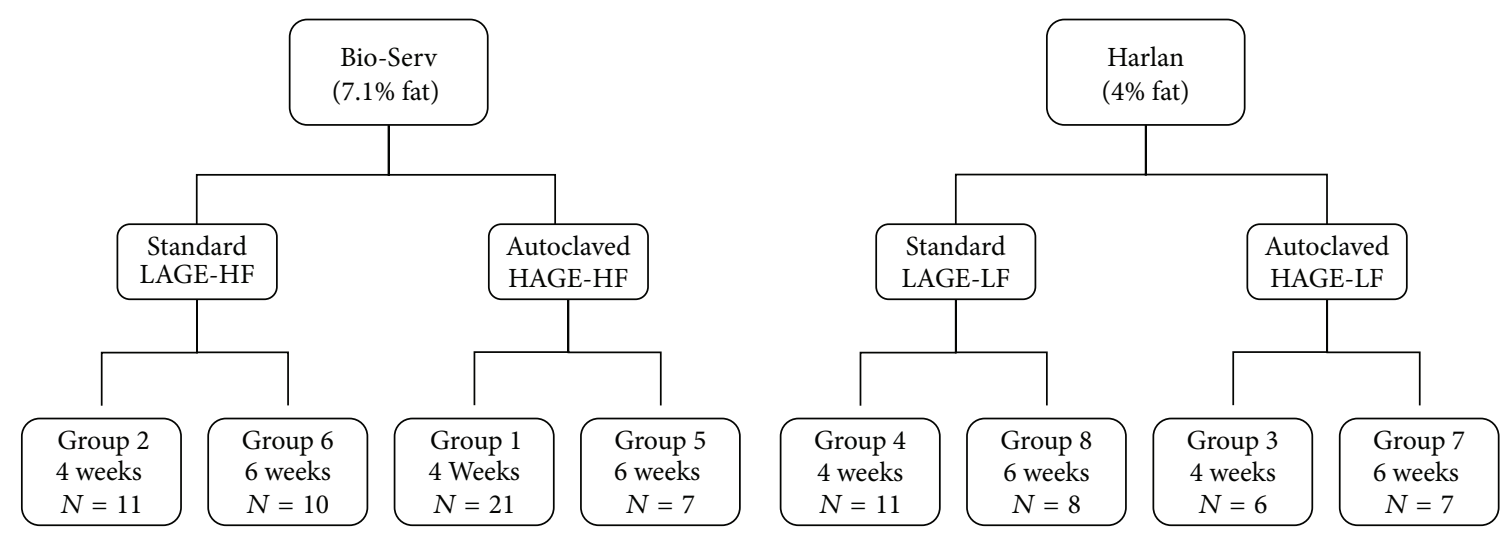

FIGURE 1: Flowchart of mice groups based on chow assigned. $N$ shows the number of mice in each group. HAGE-HF: high AGE-high fat, HAGE-LF: high AGE-low fat, LAGE-HF: low AGE-high fat, and LAGE-LF: low AGE-low fat.

of arrival to our facilities, weekly, and at time of sacrifice to measure weight gain during the period of the study.

2.3. Diet AGE Levels. Samples of the diets were crushed and sent to Dr. Peter Stahl at MicroCoat Biotechnologie GmbH Â, Bernried, Germany. The chows that were exposed to higher temperatures and for a longer period of time (autoclaved for 30 minutes at $125^{\circ} \mathrm{C}$ ) contained 4-5-fold higher AGE levels than the chow as prepared by the manufacturer. AGE levels and the nutrient content in each of the diets are listed in Table 1.
2.4. Mouse Harvest and Organ Preparations. Mice were weighed prior to sacrifice. The mice were anesthetized with $2 \%$ halothane in oxygen at a rate of $5 \mathrm{~L} / \mathrm{min}$. After induction of anesthesia, a midline abdominal/thoracic incision was made to allow full exposure of the abdominal viscera. The epididymal fat pads were resected and weighed. The inferior vena cava was transected and the heart was flushed with $5 \mathrm{~mL}$ Hank's Balanced Salt Solution (1xHBSS) with $\mathrm{Mg}^{+}$and $\mathrm{Ca}^{+}$(Life Technologies, Grand Island, NY) to completely exsanguinate the mice.

The livers were harvested and weighed. A sample from each liver was immediately immersed in formaldehyde. 
TABLE 2: Effect of the diets on weight gain, epididymal fat pad, and liver weights.

\begin{tabular}{|c|c|c|c|c|c|}
\hline & HAGE-HF & LAGE-HF & HAGE-LF & LAGE-LF & $P$ value $^{\mathrm{a}}$ \\
\hline & Group 1 & Group 2 & Group 3 & Group 4 & \\
\hline & $n=20$ & $n=11$ & $n=6$ & $n=11$ & \\
\hline \multicolumn{6}{|l|}{ Four weeks } \\
\hline Weight gain (g) & $10.4 \pm 0.7$ & $12 \pm 0.8$ & $12.3 \pm 0.6$ & $4.9 \pm 0.5$ & $<0.0001$ \\
\hline Weight $\%$ gain* & $40 \pm 4$ & $54.4 \pm 4$ & $53 \pm 3$ & $15.3 \pm 3$ & $<0.0001$ \\
\hline Fat pad weight (g) & $1.1 \pm 0.04$ & $0.6 \pm 0.06$ & $0.7 \pm 0.02$ & $0.5 \pm 0.03$ & $<0.0001$ \\
\hline Fat pad weight $\%^{* *}$ & $2.8 \pm 0.4$ & $1.7 \pm 0.6$ & $1.8 \pm 0.1$ & $1.3 \pm 0.3$ & $<0.0001$ \\
\hline Liver weight (g) & $2.1 \pm 0.06$ & $1.8 \pm 0.1$ & $2 \pm 0.04$ & $2.2 \pm 0.04$ & NS \\
\hline \multirow[t]{3}{*}{ Liver weight $\%^{* *}$} & $5.5 \pm 0.1$ & $5.4 \pm 0.2$ & $5.6 \pm 0.1$ & $5.8 \pm 0.1$ & NS \\
\hline & Group 5 & Group 6 & Group 7 & Group 8 & \\
\hline & $n=7$ & $n=10$ & $n=6$ & $n=8$ & \\
\hline \multicolumn{6}{|l|}{ Six weeks } \\
\hline Weight gain (g) & $20.4 \pm 1.0$ & $15.4 \pm 0.7$ & $14.8 \pm 0.5$ & $14.6 \pm 1.0$ & $<0.0001$ \\
\hline Weight $\%$ gain ${ }^{*}$ & $88.3 \pm 4.4$ & $69.3 \pm 3$ & $64 \pm 2.7$ & $61.4 \pm 3.7$ & $<0.0001$ \\
\hline Fat pad weight (g) & $1.6 \pm 0.05$ & $0.9 \pm 0.05$ & $0.8 \pm 0.03$ & $0.5 \pm 0.04$ & $<0.0001$ \\
\hline Fat pad weight $\%^{* *}$ & $3.7 \pm 0.3$ & $2.3 \pm 0.4$ & $2.1 \pm 0.2$ & $1.3 \pm 0.3$ & $<0.0001$ \\
\hline Liver weight (g) & $2.1 \pm 0.06$ & $2 \pm 0.01$ & $2 \pm 0.04$ & $2 \pm 0.02$ & NS \\
\hline Liver weight $\%^{* *}$ & $5.2 \pm 0.2$ & $5.3 \pm 0.1$ & $5.4 \pm 0.1$ & $5.2 \pm 0.1$ & NS \\
\hline
\end{tabular}

Values are presented with mean \pm SEM.

${ }^{a}$ We used nonparametric Kruskal-Wallis tests followed by Dunn's multiple comparisons test. Results were considered statistically significant at $P<0.05$.

${ }^{*}$ Weight $\%$ gain is expressed as weight gain in relation to initial weight of animal (final weight-initial weight/initial weight).

${ }^{* *}$ Fat pad weight $\%$ and liver weight $\%$ are expressed as weight of fat pad or liver in relation to final weight of animal (fat pad or liver weight/final weight).

The remaining liver was washed with cold HBSS and suspended in cytokine homogenate buffer $(150 \mathrm{mM} \mathrm{NaCl}, 15 \mathrm{mM}$ Tris, $1 \mathrm{mM} \mathrm{CaCl} \cdot 2 \mathrm{H}_{2} \mathrm{O}$, and $1 \mathrm{mM} \mathrm{MgCl} \cdot 6 \mathrm{H}_{2} \mathrm{O}$, adjusted to $\mathrm{pH}$ 7.4) plus $100 \mathrm{x}$ protease inhibitor cocktail 1 (Calbiochem, La Jolla, California) to a total volume of $10 \mathrm{~mL}$ and homogenized on ice using a Polytron ${ }^{\circledast}$ Homogenizer (Kinematica Inc., Bohemia, NY). The samples were centrifuged at 40,000 g for 15 minutes at $4^{\circ} \mathrm{C}$ (Avanti ${ }^{\circledast} \mathrm{J}$-E Centrifuge and JA-20 rotor, Beckman Coulter, Fullerton, CA). The supernatant between the pellet and the superficial layer (consisting mainly of fat and other tissues) was collected, transferred in aliquots to $1.5 \mathrm{~mL}$ tubes, and stored at $-80^{\circ} \mathrm{C}$ for cytokine analysis by ELISA at a later time.

2.5. Liver Histology. The tissue in formaldehyde was embedded in paraffin blocks, sliced into $4 \mu \mathrm{m}$ sections with a microtome, and fixed on glass slides. After they were deparaffinized with xylene and ethanol, they were stained with hematoxylin and eosin (H\&E) and trichrome stains. An experienced pathologist performed histologic analysis in blinded fashion. The slides were examined and photographed under a light microscope (Olympus BH-2 microscope, Olympus America Inc., Center Valley, PA).

2.6. Myeloperoxidase Assay. The pellets that remained after homogenization were suspended in myeloperoxidase homogenate buffer $(0.5 \%$ hexadecyltrimethylammonium bromide (HTAB) $(13.7 \mathrm{mM}), 5 \mathrm{mM}$ EDTA, and $50 \mathrm{mM}$ potassium phosphate $\left(\mathrm{KH}_{2} \mathrm{PO}_{4}\right)$ buffer, adjusted to $\left.\mathrm{pH}=6\right)$, sonicated for 1 minute at $50 \%$ using the Branson Sonifier 450 with a microtip probe (Branson Ultrasonics Corporation, Danbury, CT), covered with aluminum foil, incubated in a $55^{\circ} \mathrm{C}$ water bath for 2 hours, and then centrifuged again at $40,000 \mathrm{~g}$ for 15 minutes at $4^{\circ} \mathrm{C}$. The supernatants were reserved, with total volume measured, and stored at $-80^{\circ} \mathrm{C}$ until the MPO activity assay was performed.

MPO activity was measured by continuously monitoring the $\mathrm{H}_{2} \mathrm{O}_{2}$-dependent oxidation of o-dianisidine dihydrochloride $(\mathrm{ODH})$ using a SpectraMax 190 and Software Max (Molecular Devices Corporation, Sunnyvale, CA) at $460 \mathrm{~nm}$, time 90 seconds, and intervals of 2 seconds which gave us 46 reads. MPO activity was expressed as the absorbance change at $460 \mathrm{~nm}$ (ABS) per minute over the linear portion of the curve and normalized to the total volume extracted from the liver.

2.7. Cytokine Analysis. Quantification of leptin, interleukin-6 (IL-6), and TNF-alpha (TNF- $\alpha$ ) in cell free supernatants was determined by enzyme-linked immunoassays (ELISA) with ELISA kits from R\&D systems (Minneapolis, MN).

2.8. Statistical Analysis. All data are expressed as mean \pm SEM. We used Kruskal-Wallis tests followed by Dunn's multiple comparisons test and Mann-Whitney test (nonparametric) to determine statistical significance when comparing 2 groups, with $\alpha$ error set to 0.05 , to control for multiple comparisons using GraphPad Prism 5.0 ${ }^{\circledR}$ software (GraphPad Software, Inc., San Diego, CA). Values for myeloperoxidase and cytokines were log transformed prior to performing statistical analysis to normalize data. Pearson correlation was 


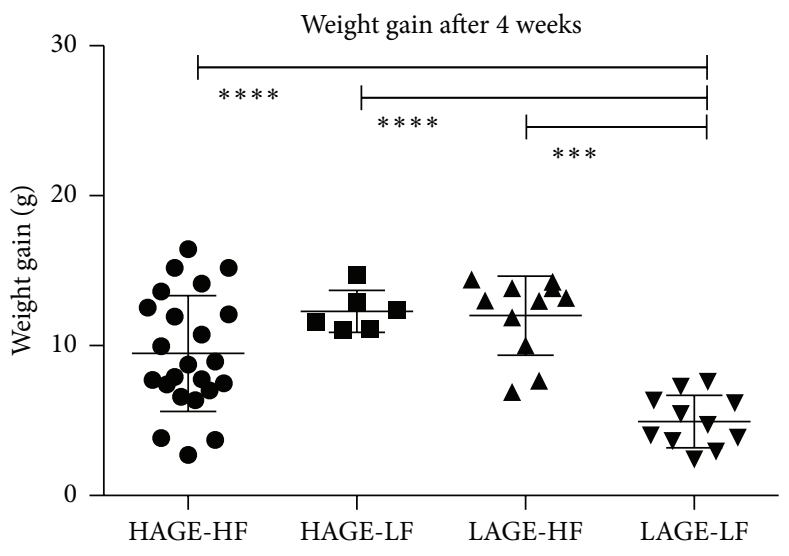

(a)

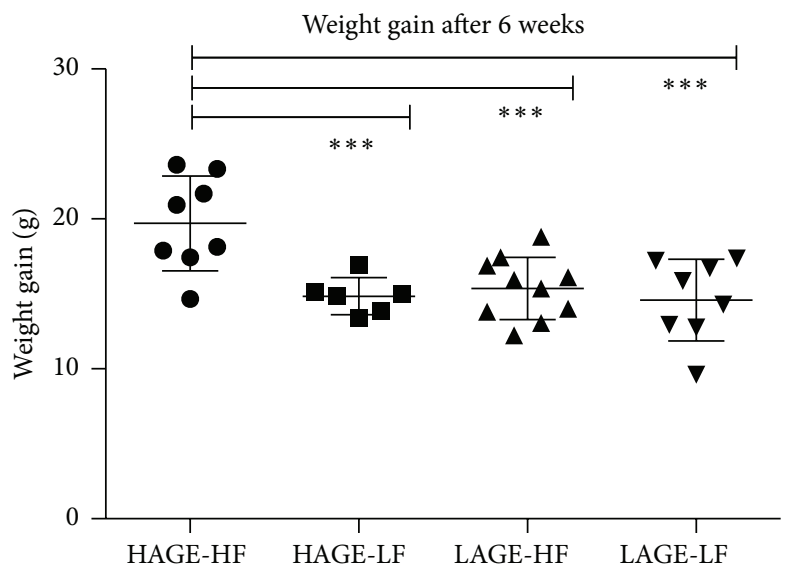

(c)

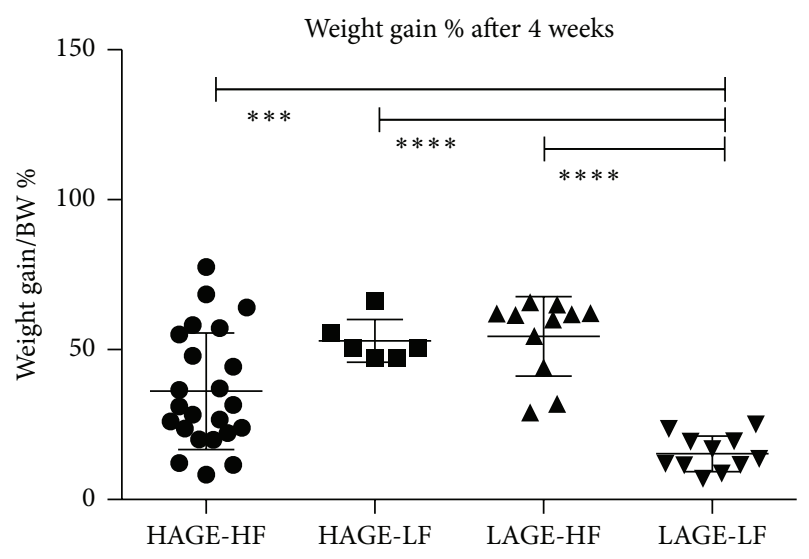

(b)

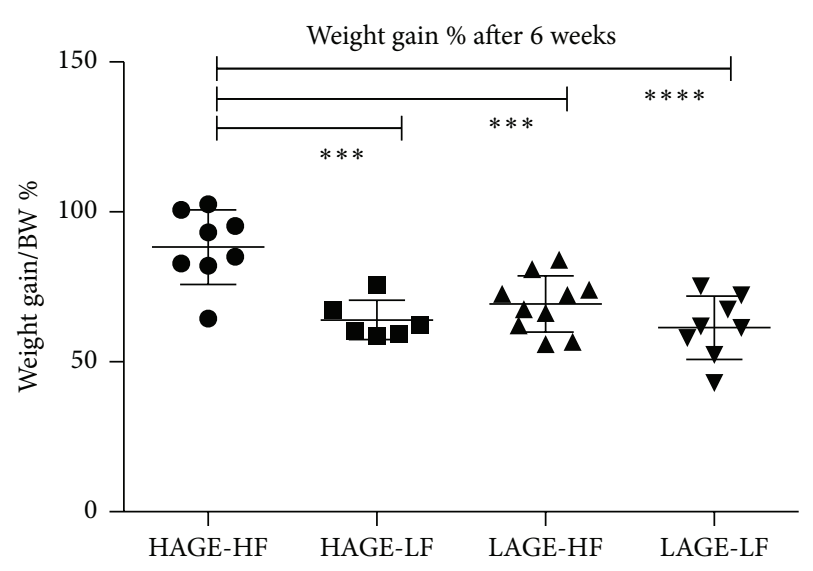

(d)

FIGURE 2: Weight gain comparisons. (a) Weight gain at 4 weeks in each group based on the different diets. (b) Weight gain as percentage of final body weight at 4 weeks. (c) Weight gain at 6 weeks in each group based on the different diets. (d) Weight gain as percentage of final body weight at 6 weeks. ${ }^{* * * *} P<0.0001,{ }^{* * *} P<0.001$.

performed to determine the linear correlation between MPO activity and weight gain percentage (\%) to initial weight or fat pad $\%$ of final weights. A $P$ value of $<0.05$ was considered statistically significant.

\section{Results}

3.1. Effect of Diet on Weight Gain. To determine the effects of each diet on weight gain, the mice were weighed at arrival (4 weeks old), weekly, and at time of sacrifice ( 8 weeks and 10 weeks old). To take into consideration variations in initial weight of mice, the weight gain (grams) was calculated as a percentage of the final weight of the mice. After 4 weeks on the diets, LAGE-LF (group 4) mice had significantly less weight gain than the other 3 groups. After 6 weeks on the diets mice that were fed the HAGE-HF chow (group 5) had the most weight gain $(20.4 \mathrm{~g} \pm 1.0 ; 88.3 \% \pm 4.4)$ compared to the other three groups, $P<0.0001$. Additionally, there was a significant difference in weight gain when HAGE-HF (group 5) was compared to the individual groups: versus LAGE-HF (group 6) $(15.4 \mathrm{~g} \pm 0.7 ; 69.3 \% \pm 4), P=0.001$; versus HAGELF (group 7) (14.8 g $\pm 0.5 ; 64 \% \pm 2.7), P=0.0005$; and versus
LAGE-LF (group 8) $(14.6 \mathrm{~g} \pm 1.0 ; 61.4 \% \pm 3.7), P=0.0002$. Table 2 summarizes the weight gain means \pm standard error (SEM) for each group of mice according to the diets that they were given and Figure 2 demonstrates the differences in weight gain and weight gain as $\%$ of final weight at 4 weeks and 6 weeks.

3.2. Epididymal Fat Pads. Adipose tissue stores lipids in the form of triglycerides when energy intake exceeds expenditure. Epididymal fat pads from mice fed the HAGE-HF diet for 4 and 6 weeks (groups 1 and 5) were heavier and a higher percent of body weight compared to those fed LAGE-HF, HAGE-LF, or LAGE-LF. There was no difference between the LAGE-HF group and the HAGE-LF group in fat pad weight or percent body weight at 4 and 6 weeks. Fat pads from the LAGE-LF group were small in both average weight and percent body weight at 4 and 6 weeks when compared to either the LAGE-HF group or the HAGE-LF group. Table 2 summarizes the epididymal fat pad weights expressed in mean \pm SEM and as mean percentage of final body weights \pm SEM for each group of mice according to the diets that they were given and Figure 3 demonstrates the differences 


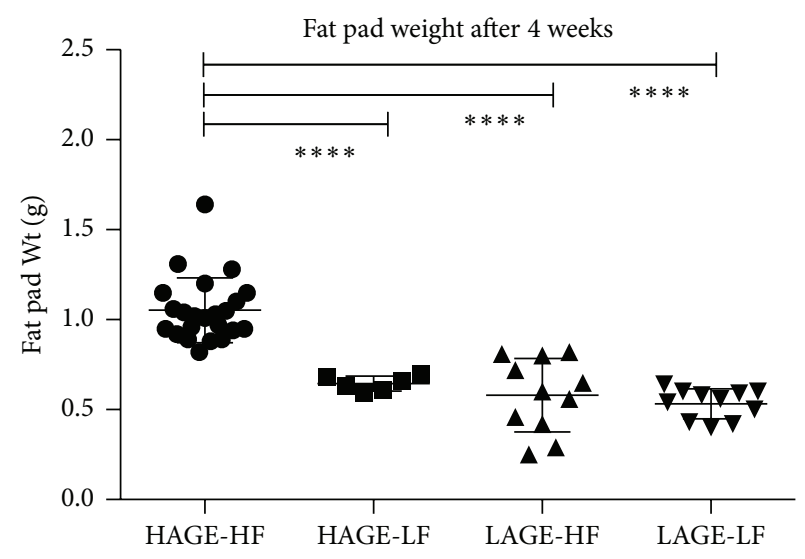

(a)

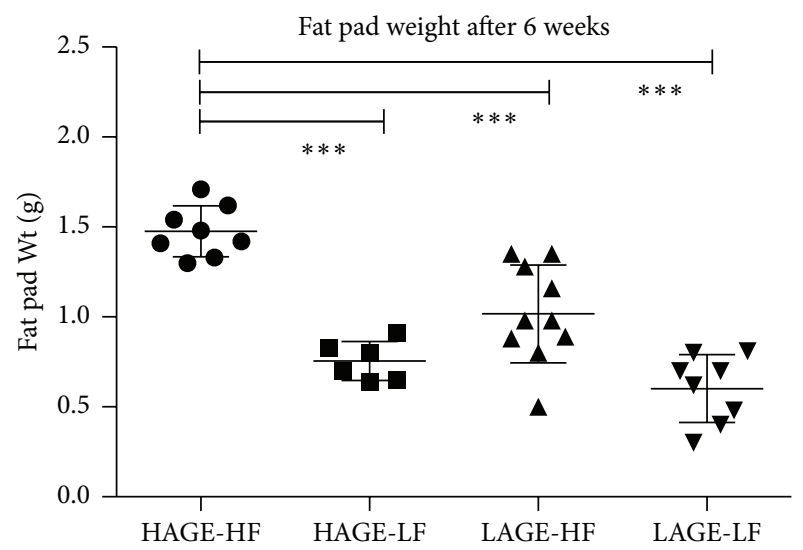

(c)

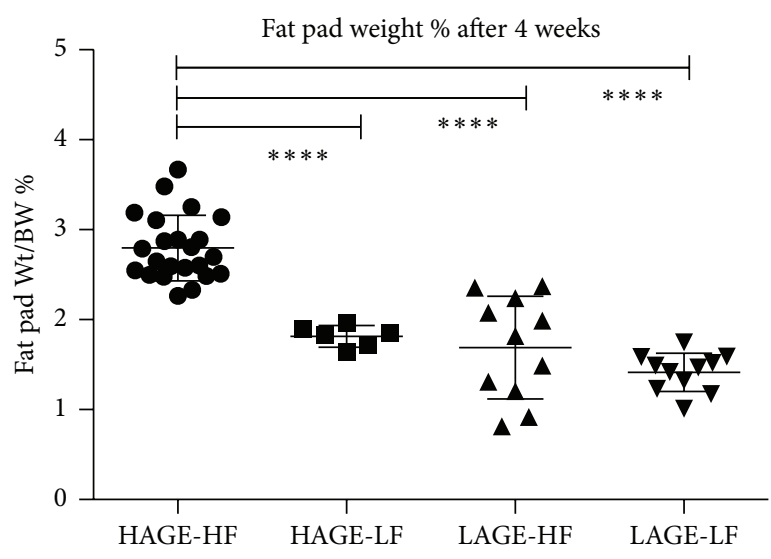

(b)

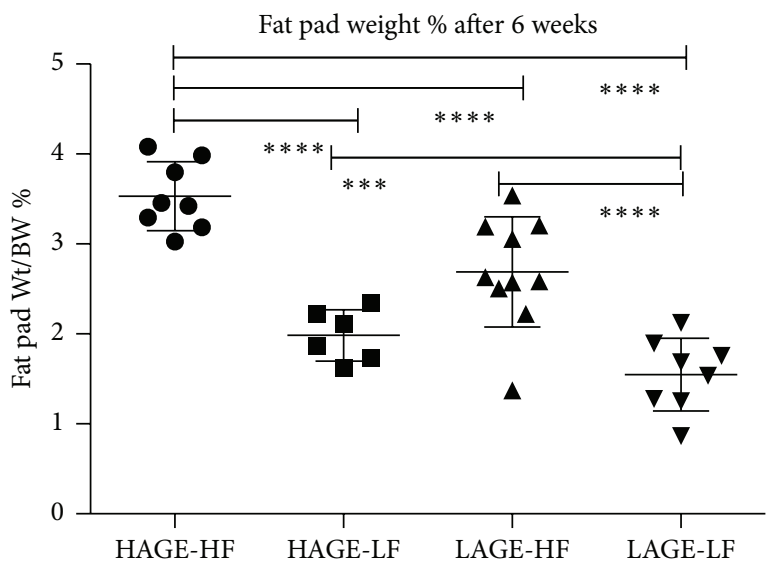

(d)

Figure 3: Epididymal fat pad weight comparisons. (a) Epididymal fat pad weight at 4 weeks of comparison. (b) Epididymal fat pad weight as percentage of final weight at 4 weeks. (c) Epididymal fat pad weight at 6 weeks of comparison. (d) Epididymal fat pad weight as percentage of final weight at 6 weeks. ${ }^{* * *} P<0.0001,{ }^{* * *} P<0.001$.

in epididymal fat pad weight and weight as percent of final weight at 4 weeks and 6 weeks.

3.3. Effects of Diet on Liver Weight. Table 2 shows that whole wet liver weights were not significantly different in any of the groups after 4 and 6 weeks on the diets.

3.4. Histology. Histology of liver shows that microvesicular steatosis had developed in all groups except for those fed the LAGE-LF. After 6 weeks on the chow, the mice in the HAGE-HF also had evidence of progression to macrovesicular steatosis. Steatohepatitis (inflammation) was seen in approximately $40 \%$ of the mice that received the HAGEHF chow after 6 weeks. No inflammation was seen in the LAGE-LF groups. Figure 4 shows H\&E staining representing a randomly selected set of slides per group of mice after 4 weeks and 6 weeks on the diets, respectively. Trichrome staining did not show evidence of fibrosis in any of the groups.

3.5. Myeloperoxidase Activity. Liver MPO activity was significantly higher in the groups that received the HAGEHF diet than the other groups after 4 weeks and 6 weeks;
$P<0.0001$ and $P=0.0001$, respectively. This is consistent with the acute liver inflammation observed with histology. There was no significant difference in the other groups after 4 weeks or 6 weeks. Figure 5 summarizes the MPO activity results expressed as (ABS/min/liver) \pm SEM. MPO activity also significantly correlated with weight gain and epididymal fat pad weight at 4 and 6 weeks.

3.6. Cytokine Analysis. The proinflammatory cytokine tumor necrosis factor- $\alpha$ (TNF- $\alpha$ ) is synthesized and released by adipocytes [54] and may play a role in the induction of insulin resistance. $[55,56]$ TNF- $\alpha$ levels were not significantly different after 4 weeks on the diets $(P=0.47)$ (Figure 6). However, after 6 weeks, the HAGE-HF chow fed mice had higher TNF- $\alpha$ levels compared to the LAGE-HF group ( $P=$ $0.0002)$, the HAGE-LF group $(P=0.01)$, and the LAGE-LF group $(P=0.006)$, respectively (Figure 6). Additionally, the HAGE-LF group had higher levels than the LAGE-HF and LAGE-LF groups, which may indicate that the AGE content and not the fat content is what contributed to the elevated levels of TNF- $\alpha$ (Figure 6). 

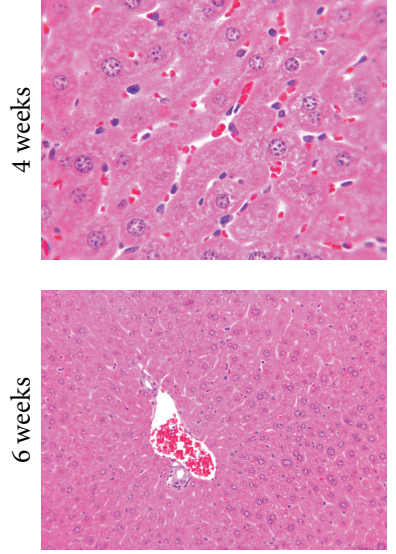

LAGE-LF
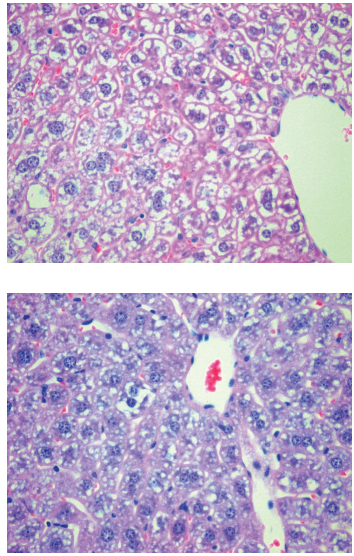

LAGE-HF
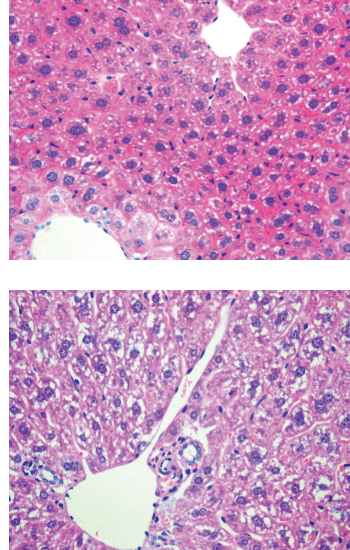

HAGE-LF
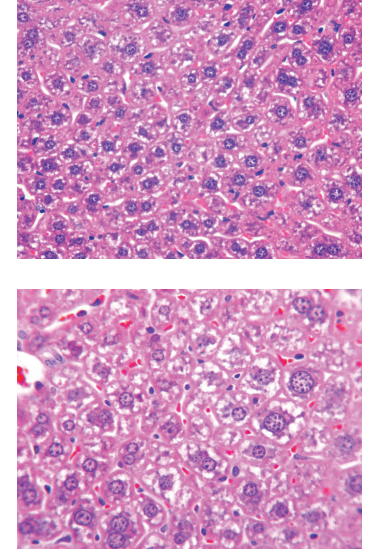

HAGE-HF

FIGURE 4: Hematoxylin and eosin staining of liver tissues showing normal histology in the LAGE-LF groups after 4 and 6 weeks; varying degrees of steatosis in all other groups and mixed micro- and macrovesicular steatosis and mild steatohepatitis in the HAGE-HF groups after 4 and 6 weeks.

TNF- $\alpha$ induces the release of IL- 6 from several cell types. Circulating IL-6 stimulates the hypothalamic-pituitaryadrenal (HPA) axis, activation of which is associated with central obesity, hypertension, and insulin resistance. As expected, IL-6 levels were significantly elevated in the HAGE-HF groups compared to the other groups at 4 weeks $(P=0.02)$ and at 6 weeks $(P=0.005)$, respectively (Figure 6$)$.

\section{Discussion}

Mice fed the HAGE-HF diet accumulated more fat than the other group as shown by the larger weight gain and larger epididymal fat pad. There was no significant difference in liver weight among all groups. Some HAGE-HF fed mice showed evidence of hepatosteatosis and steatohepatitis. There was mild, if any, hepatosteatosis seen in the LAGE-HF fed mice. Diets high in fat content are associated with weight gain and obesity and energy consumed in excess of requirements is stored in the form of triglycerides in adipose tissues. It was not surprising that the mice fed the HAGE-HF developed hepatosteatosis and/or steatohepatitis and the mice that were fed the LAGE-LF diet had normal liver histology. However, the mice that were fed the HAGE-LF had similar outcomes as the mice that were fed the LAGE-HF in terms of weight gain and epididymal fat pad findings. There was evidence of mild hepatosteatosis in these groups. Additionally, mice that were fed the HAGE-HF had significantly more weight gain and higher epididymal fat pad weights compared to the HAGELF and the LAGE-HF fed mice. This suggests that AGEs likely played a role in the development of hepatosteatosis.

In addition to the liver fat, MPO activity was increased in mice on HAGE-HF. As MPO is an indicator of organ inflammation with acute neutrophilic infiltration, this indicates that AGEs may contribute to liver inflammation.

Leptin is an adipose derived protein hormone that plays important roles in regulating food intake and energy expenditure, including appetite and metabolism [57]. It is a circulatory biomarker that is proportional to body fat. Leptin levels control food intake and energy expenditure by acting on receptors in the mediobasal hypothalamus [58]. In obesity, a putative resistance to leptin develops, which prevents the normal negative feedback control mechanism responsible for adipocyte leptin production from functioning properly [59]. This leads to elevated plasma levels of leptin. The increased leptin levels found in the HAGE-HF fed mice suggest the leptin resistance to obesity and fatty liver, as well as the inflammation in these fatty livers. It is possible, however, that other adipokines may play a role.

Finally there is clear evidence of a heightened proinflammatory state in the mice that were fed the HAGE-HF chow. In obesity, inflammation occurs due to altered metabolic homeostasis in accordance with dietary intake. This leads to upregulation of proinflammatory genes (TNF- $\alpha$, IL-6, CRP, leptin, and IL-1 $\beta$ ) and downregulation of anti-inflammatory genes (IL-10, IL-Ra, and adiponectin) encoding for the respective cytokines, chemokines, and adipokines [60]. The proinflammatory cytokine tumor necrosis factor- $\alpha$ (TNF$\alpha$ ) is synthesized and released by adipocytes [54] and has been shown to play a role in the induction of insulin resistance $[55,56]$. Additionally, TNF- $\alpha$ and IL- 6 are strong mediators of insulin resistance, which is the best-examined link in the pathogenesis of polycystic ovarian syndrome [61]. Lipopolysaccharide (LPS) has been shown to be one of the major players in nonalcoholic fatty liver disease pathogenesis and progression. It has been shown to induce a proinflammatory and profibrogenic phenotype of NASH via LPS induced TNF- $\alpha$-dependent transcription of TNF- $\alpha$, IL- 6 , and IL- $1 \beta$ [62]. TNF- $\alpha$ and IL- 6 are both elevated in the liver tissues of mice fed a HAGE-HF chow. This is consistent with MPO activity and histology of the liver, indicative of acute neutrophilic infiltration in the liver. Elevated levels of TNF$\alpha$ and the soluble receptors of this cytokine are consistent with a continuing inflammatory state. TNF- $\alpha$ enhances the release of IL- 6 from in a number of cell types especially adipocytes. IL- 6 is a potent inducer of the hepatic acute phase response observed in many systemic inflammatory responses 

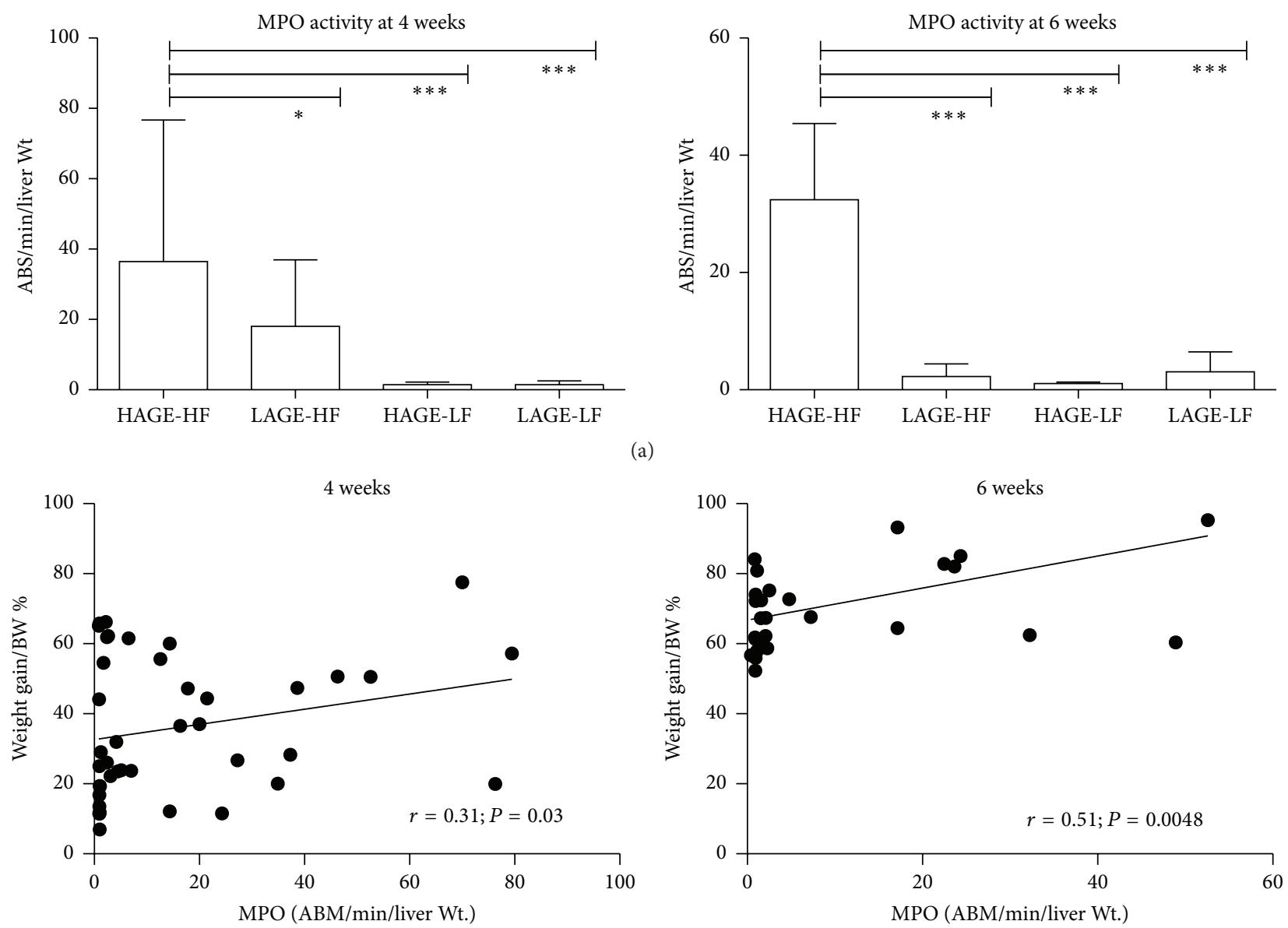

(b)
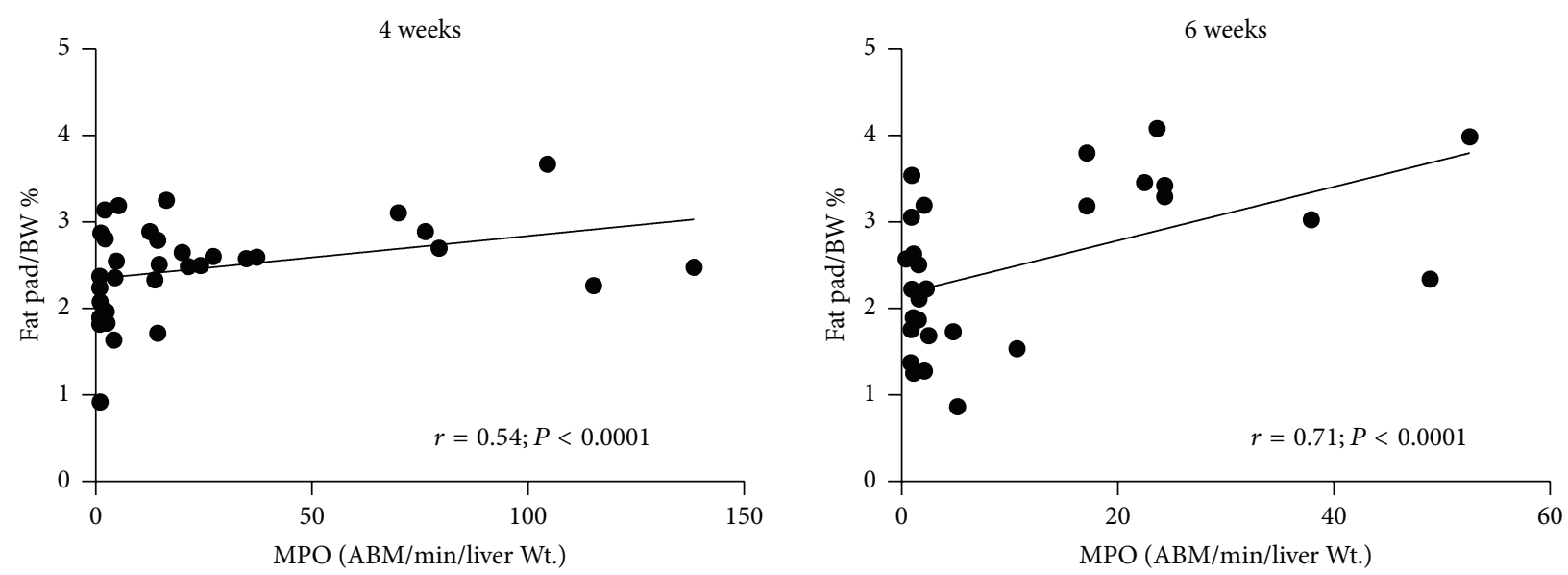

(c)

FIGURE 5: Myeloperoxidase activity in liver tissues. (a) MPO activity is highest in the HAGE-HF groups after 4 and 6 weeks. (b) MPO activity strongly correlates with weight gain. (c) MPO activity strongly correlates with epididymal fat pad weights. 

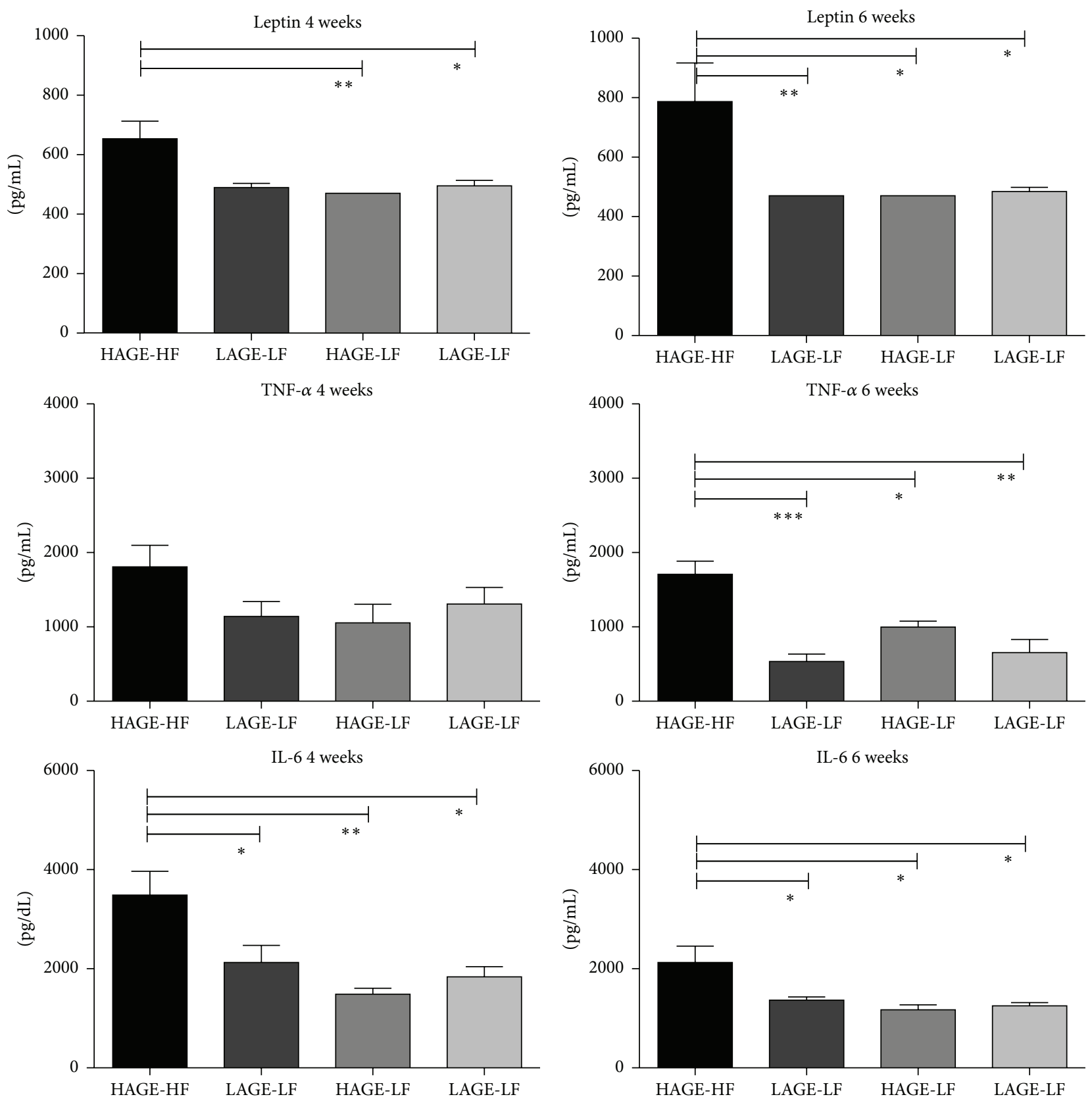

FIGURE 6: Leptin and cytokine levels (IL- 6 and TNF- $\alpha$ ) after 4 and 6 weeks on the diets. Consistent with the weight gain and epididymal fat pad weights, leptin levels were significantly higher after 4 and 6 weeks in the HAGE-HF group compared to the other groups. Also consistent with the liver histology and presence of inflammation after 6 weeks on the diet, IL- 6 and TNF- $\alpha$ levels were significantly higher in the HAGE-HF group after 6 weeks on the diet.

(i.e., sepsis). It has also been proposed that IL-6 released from adipocytes stimulates hepatic synthesis of $\mathrm{C}$-reactive protein (CRP) in obesity [63-65]. Additionally, increased circulating IL-6 levels stimulate the hypothalamic-pituitary-adrenal (HPA) axis, which plays an important role in control of central obesity, hypertension, insulin resistance, and PCOS. Hypothalamic inflammation has been shown to be associated with high fat diet intake in rats and increased expression of hypothalamic TLR-4, NF- $\kappa \beta$, TNF- $\alpha$, IL-1 $\beta$, and IL-6 [66].
Our study has some limitations. We only investigated the local inflammation in the livers but did not evaluate the systemic inflammatory markers. Thus, we could not define the relationship between systemic inflammation and NAFLD.

\section{Conclusions}

Diets containing high AGEs and fat contribute to obesity and NAFLD in CD-1 mice, which are associated with increased 
inflammation of the liver. This suggests that dietary AGEs coupled with high fat play an important role in the development of obesity and NAFLD, possibly by promoting a proinflammatory state. These findings warrant further study as they may represent a model that can be used to study the pathogenesis of NAFLD.

$\begin{array}{ll}\text { Abbreviations } \\ \text { BS: } & \text { Bio-Serv } \\ \text { HT: } & \text { Harlan-Tek } \\ \text { AGEs: } & \text { Advanced glycation end products } \\ \text { HAGE: } & \text { High AGE } \\ \text { LAGE: } & \text { Low AGE } \\ \text { HF: } & \text { High fat } \\ \text { LF: } & \text { Low fat } \\ \text { IL-6: } & \text { Interleukin-6 } \\ \text { TNF- } \alpha: & \text { Tumor necrosis factor- } \alpha \\ \text { MPO: } & \text { Myeloperoxidase } \\ \text { RAGE: } & \text { Receptor for AGE } \\ \text { ELISA: } & \text { Enzyme-linked immunoassay } \\ \text { NAFLD: } & \text { Nonalcoholic fatty liver disease } \\ \text { SEM: } & \text { Standard error of the mean. }\end{array}$

\section{Conflict of Interests}

The authors have no financial or nonfinancial competing interests.

\section{Authors' Contribution}

Wael N. Sayej designed project and experimental design, carried out tissue harvesting and experiments, performed data analysis, and wrote paper drafts and final paper. Paul R. Knight III, research mentor, helped with experimental design and helped with paper draft. Weidun Alan Guo helped with paper design and harvesting of tissue. Barbara Mullan and Patricia J. Ohtake helped with harvesting of tissue and helped carry out experiments. Bruce A. Davidson helped with statistical analysis and paper draft. Robert D. Baker and Susan S. Baker helped with paper final revision, experiment design, data analysis, and paper drafts.

\section{Acknowledgments}

This study was supported by NIH Grant no. HL48889 (Paul R. Knight III) and the Peter and Tommy Fund, Inc. (Susan S. Baker).

\section{References}

[1] Y. Falck-Ytter, Z. M. Younossi, G. Marchesini, and A. J. McCullough, "Clinical features and natural history of nonalcoholic steatosis syndromes," Seminars in Liver Disease, vol. 21, no. 1, pp. 17-26, 2001.

[2] J. M. Clark, F. L. Brancati, and A. M. Diehl, "Nonalcoholic fatty liver disease," Gastroenterology, vol. 122, no. 6, pp. 1649-1657, 2002.
[3] J. D. Browning and J. D. Horton, "Molecular mediators of hepatic steatosis and liver injury," The Journal of Clinical Investigation, vol. 114, no. 2, pp. 147-152, 2004.

[4] I. R. Wanless and K. Shiota, "The pathogenesis of nonalcoholic steatohepatitis and other fatty liver diseases: a four-step model including the role of lipid release and hepatic venular obstruction in the progression to cirrhosis," Seminars in Liver Disease, vol. 24, no. 1, pp. 99-106, 2004.

[5] C. P. Day and O. F. James, "Steatohepatitis: a tale of two "hits"?" Gastroenterology, vol. 114, no. 4, pp. 842-845, 1998.

[6] C. P. Day, "Pathogenesis of steatohepatitis," Bailliere's Best Practice and Research in Clinical Gastroenterology, vol. 16, no. 5, pp. 663-678, 2002.

[7] C. J. McClain, S. P. L. Mokshagundam, S. S. Barve et al., "Mechanisms of non-alcoholic steatohepatitis," Alcohol, vol. 34, no. 1, pp. 67-79, 2004.

[8] G. Marchesini, M. Brizi, A. M. Morselli-Labate et al., "Association of nonalcoholic fatty liver disease with insulin resistance," American Journal of Medicine, vol. 107, no. 5, pp. 450-455, 1999.

[9] K. Nanda, "Non-alcoholic steatohepatitis in children," Pediatric Transplantation, vol. 8, no. 6, pp. 613-618, 2004.

[10] S. Ten and N. Maclaren, "Insulin resistance syndrome in children," The Journal of Clinical Endocrinology \& Metabolism, vol. 89, no. 6, pp. 2526-2539, 2004.

[11] C. J. McClain, Z. Song, S. S. Barve, D. B. Hill, and I. Deaciuc, "Recent advances in alcoholic liver disease. IV. Dysregulated cytokine metabolism in alcoholic liver disease," The American Journal of Physiology-Gastrointestinal and Liver Physiology, vol. 287, no. 3, pp. G497-G502, 2004.

[12] G. C. Farrell and C. Z. Larter, "Nonalcoholic fatty liver disease: from steatosis to cirrhosis," Hepatology, vol. 43, no. 2, supplement 1, pp. S99-S112, 2006.

[13] M. H. Fishbein, C. Mogren, T. Gleason, and W. R. Stevens, "Relationship of hepatic steatosis to adipose tissue distribution in pediatric nonalcoholic fatty liver disease," Journal of Pediatric Gastroenterology and Nutrition, vol. 42, no. 1, pp. 83-88, 2006.

[14] S. Horiuchi, "The liver is the main site for metabolism of circulating advanced glycation end products," Journal of Hepatology, vol. 36, no. 1, pp. 123-125, 2002.

[15] D. Svistounov and B. Smedsrød, "Hepatic clearance of advanced glycation end products (AGEs) - myth or truth?" Journal of Hepatology, vol. 41, no. 6, pp. 1038-1040, 2004.

[16] H. Hyogo, S.-I. Yamagishi, K. Iwamoto et al., "Elevated levels of serum advanced glycation end products in patients with non-alcoholic steatohepatitis," Journal of Gastroenterology and Hepatology, vol. 22, no. 7, pp. 1112-1119, 2007.

[17] K. Iwamoto, K. Kanno, H. Hyogo et al., "Advanced glycation end products enhance the proliferation and activation of hepatic stellate cells," Journal of Gastroenterology, vol. 43, no. 4, pp. 298304, 2008.

[18] M. Takeuchi, A. Sakasai-Sakai, T. Takata et al., "Serum levels of toxic AGEs (TAGE) may be a promising novel biomarker in development and progression of NASH," Medical Hypotheses, vol. 84, no. 5, pp. 490-493, 2015.

[19] C. Sharma, A. Kaur, S. S. Thind, B. Singh, and S. Raina, "Advanced glycation end-products (AGEs): an emerging concern for processed food industries," Journal of Food Science and Technology, vol. 52, no. 12, pp. 7561-7576, 2015.

[20] C. Cerami, H. Founds, I. Nicholl et al., "Tobacco smoke is a source of toxic reactive glycation products," Proceedings of the National Academy of Sciences of the United States of America, vol. 94, no. 25, pp. 13915-13920, 1997. 
[21] S. Yamagishi, T. Matsui, and K. Nakamura, "Possible involvement of tobacco-derived advanced glycation end products (AGEs) in an increased risk for developing cancers and cardiovascular disease in former smokers," Medical Hypotheses, vol. 71, no. 2, pp. 259-261, 2008.

[22] T. Kimura, J. Takamatsu, K. Ikeda, A. Kondo, T. Miyakawa, and S. Horiuchi, "Accumulation of advanced glycation end products of the Maillard reaction with age in human hippocampal neurons," Neuroscience Letters, vol. 208, no. 1, pp. 53-56, 1996.

[23] J. W. Baynes, "The role of AGEs in aging: causation or correlation," Experimental Gerontology, vol. 36, no. 9, pp. 1527-1537, 2001.

[24] J. W. Baynes, "The Maillard hypothesis on aging: time to focus on DNA," Annals of the New York Academy of Sciences, vol. 959, pp. 360-367, 2002.

[25] T. Buetler and T. Henle, "The effects of AGEing on diet," The American Journal of Pathology, vol. 174, no. 1, pp. 351-353, 2009.

[26] W. Cai, J. C. He, L. Zhu et al., "Oral glycotoxins determine the effects of calorie restriction on oxidant stress, age-related diseases, and lifespan," The American Journal of Pathology, vol. 173, no. 2, pp. 327-336, 2008.

[27] C.-D. Agardh, U. Stenram, O. Torffvit, and E. Agardh, "Effects of inhibition of glycation and oxidative stress on the development of diabetic nephropathy in rats," Journal of Diabetes and Its Complications, vol. 16, no. 6, pp. 395-400, 2002.

[28] B. O. Boehm, S. Schilling, S. Rosinger et al., "Elevated serum levels of N(epsilon)-carboxymethyl-lysine, an advanced glycation end product, are associated with proliferative diabetic retinopathy and macular oedema," Diabetologia, vol. 47 , no. 8 , pp. 1376-1379, 2004.

[29] T. Koschinsky, C.-J. He, T. Mitsuhashi et al., "Orally absorbed reactive glycation products (glycotoxins): an environmental risk factor in diabetic nephropathy," Proceedings of the National Academy of Sciences of the United States of America, vol. 94, no. 12, pp. 6474-6479, 1997.

[30] M. U. Ahmed, E. Brinkmann Frye, T. P. Degenhardt, S. R. Thorpe, and J. W. Baynes, "N-epsilon-(carboxyethyl)lysine, a product of the chemical modification of proteins by methylglyoxal, increases with age in human lens proteins," The Biochemical Journal, vol. 324, part 2, pp. 565-570, 1997.

[31] M. Takahashi, H. Hoshino, K. Kushida, K. Kawana, and T. Inoue, "Direct quantification of pentosidine in urine and serum by HPLC with column switching," Clinical Chemistry, vol. 42, no. 9, pp. 1439-1444, 1996.

[32] R. Ramasamy, S. F. Yan, and A. M. Schmidt, "Methylglyoxal comes of AGE," Cell, vol. 124, no. 2, pp. 258-260, 2006.

[33] T. Niwa, T. Katsuzaki, S. Miyazaki et al., "Immunohistochemical detection of imidazolone, a novel advanced glycation end product, in kidneys and aortas of diabetic patients," The Journal of Clinical Investigation, vol. 99, no. 6, pp. 1272-1280, 1997.

[34] P. J. Thornalley, S. Battah, N. Ahmed et al., "Quantitative screening of advanced glycation endproducts in cellular and extracellular proteins by tandem mass spectrometry," Biochemical Journal, vol. 375, no. 3, pp. 581-592, 2003.

[35] N. Ahmed and P. J. Thornalley, "Quantitative screening of protein biomarkers of early glycation, advanced glycation, oxidation and nitrosation in cellular and extracellular proteins by tandem mass spectrometry multiple reaction monitoring," Biochemical Society Transactions, vol. 31, no. 6, pp. 1417-1422, 2003.
[36] E. Yagmur, F. Tacke, C. Weiss et al., "Elevation of $\mathrm{N} \varepsilon$ (carboxymethyl)lysine-modified advanced glycation end products in chronic liver disease is an indicator of liver cirrhosis," Clinical Biochemistry, vol. 39, no. 1, pp. 39-45, 2006.

[37] R. Ramasamy, S. J. Vannucci, S. S. D. Yan, K. Herold, S. F. Yan, and A. M. Schmidt, "Advanced glycation end products and RAGE: a common thread in aging, diabetes, neurodegeneration, and inflammation," Glycobiology, vol. 15, no. 7, pp. 16R28R, 2005.

[38] R. Abe and S.-I. Yamagishi, "AGE-RAGE system and carcinogenesis," Current Pharmaceutical Design, vol. 14, no. 10, pp. 940945, 2008.

[39] K. Hiwatashi, S. Ueno, K. Abeyama et al., "A novel function of the receptor for advanced glycation end-products (RAGE) in association with tumorigenesis and tumor differentiation of HCC," Annals of Surgical Oncology, vol. 15, no. 3, pp. 923-933, 2008.

[40] H. Kuniyasu, Y. Chihara, and H. Kondo, "Differential effects between amphoterin and advanced glycation end products on colon cancer cells," International Journal of Cancer, vol. 104, no. 6, pp. 722-727, 2003.

[41] B. Bartling, N. Demling, R.-E. Silber, and A. Simm, "Proliferative stimulus of lung fibroblasts on lung cancer cells is impaired by the receptor for advanced glycation end-products," American Journal of Respiratory Cell and Molecular Biology, vol. 34, no. 1, pp. 83-91, 2006.

[42] P. Tesařová, M. Kalousová, M. Jáchymová, O. Mestek, L. Petruzelka, and T. Zima, "Receptor for advanced glycation end products (RAGE) - soluble form (sRAGE) and gene polymorphisms in patients with breast cancer," Cancer Investigation, vol. 25, no. 8, pp. 720-725, 2007.

[43] M. P. Vitek, K. Bhattacharya, J. M. Glendening et al., "Advanced glycation end products contribute to amyloidosis in Alzheimer disease," Proceedings of the National Academy of Sciences of the United States of America, vol. 91, no. 11, pp. 4766-4770, 1994.

[44] S. Y. Ko, H. A. Ko, K. H. Chu et al., "The possible mechanism of Advanced Glycation End Products (AGEs) for Alzheimer's disease," PLoS ONE, vol. 10, no. 11, Article ID e0143345, 2015.

[45] H. Unoki, H. Bujo, S.-I. Yamagishi, M. Takeuchi, T. Imaizumi, and Y. Saito, "Advanced glycation end products attenuate cellular insulin sensitivity by increasing the generation of intracellular reactive oxygen species in adipocytes," Diabetes Research and Clinical Practice, vol. 76, no. 2, pp. 236-244, 2007.

[46] M. Chen, T. M. Curtis, and A. W. Stitt, "Advanced glycation end products and diabetic retinopathy," Current Medicinal Chemistry, vol. 20, no. 26, pp. 3234-3240, 2013.

[47] D. L. Vander Jagt, "Methylglyoxal, diabetes mellitus and diabetic complications," Drug Metabolism and Drug Interactions, vol. 23, no. 1-2, pp. 93-124, 2008.

[48] J. Su, P. A. Lucchesi, R. A. Gonzalez-Villalobos et al., "Role of advanced glycation end products with oxidative stress in resistance artery dysfunction in type 2 diabetic mice," Arteriosclerosis, Thrombosis, and Vascular Biology, vol. 28, no. 8, pp. 1432-1438, 2008.

[49] K. Šebeková, V. Kupčová, R. Schinzel, and A. Heidland, "Markedly elevated levels of plasma advanced glycation end products in patients with liver cirrhosis-amelioration by liver transplantation," Journal of Hepatology, vol. 36, no. 1, pp. 66-71, 2002.

[50] N. Ahmed, P. J. Thornalley, R. Lüthen et al., "Processing of protein glycation, oxidation and nitrosation adducts in the liver 
and the effect of cirrhosis," Journal of Hepatology, vol. 41, no. 6 , pp. 913-919, 2004.

[51] H. Hyogo and S.-I. Yamagishi, "Advanced glycation end products (AGEs) and their involvement in liver disease," Current Pharmaceutical Design, vol. 14, no. 10, pp. 969-972, 2008.

[52] K. E. Davis, C. Prasad, P. Vijayagopal, S. Juma, B. Adams-Huet, and V. Imrhan, "Contribution of dietary advanced glycation end products (AGE) to circulating AGE: role of dietary fat," British Journal of Nutrition, vol. 114, no. 11, pp. 1797-1806, 2015.

[53] C. Leung, C. B. Herath, Z. Jia et al., "Dietary glycotoxins exacerbate progression of experimental fatty liver disease," Journal of Hepatology, vol. 60, no. 4, pp. 832-838, 2014.

[54] G. S. Hotamisligil, N. S. Shargill, and B. M. Spiegelman, "Adipose expression of tumor necrosis factor-alpha: direct role in obesity-linked insulin resistance," Science, vol. 259, no. 5091, pp. 87-91, 1993.

[55] B. M. Spiegelman and G. S. Hotamisligil, "Through thick and thin: wasting, obesity, and TNF $\alpha$," Cell, vol. 73, no. 4, pp. 625$627,1993$.

[56] G. S. Hotamisligil, P. Arner, J. F. Caro, R. L. Atkinson, and B. M. Spiegelman, "Increased adipose tissue expression of tumor necrosis factor- $\alpha$ in human obesity and insulin resistance," The Journal of Clinical Investigation, vol. 95, no. 5, pp. 2409-2415, 1995.

[57] L. M. Frago and J. A. Chowen, "Hypothalamic leptin and ghrelin signaling as targets for improvement in metabolic control," Current Pharmaceutical Design, vol. 21, no. 25, pp. 3596-3605, 2015.

[58] K. W. Williams, M. M. Scott, and J. K. Elmquist, "From observation to experimentation: leptin action in the mediobasal hypothalamus," The American Journal of Clinical Nutrition, vol. 89, no. 3, pp. 985S-990S, 2009.

[59] E. Balland and M. A. Cowley, "New insights in leptin resistance mechanisms in mice," Frontiers in Neuroendocrinology, vol. 39, pp. 59-65, 2015.

[60] M. Debnath, S. Agrawal, A. Agrawal, and G. P. Dubey, "Metaflammatory responses during obesity: pathomechanism and treatment," Obesity Research \& Clinical Practice, 2015.

[61] M. Banaś, M. Olszanecka-Glinianowicz, and B. ZahorskaMarkiewicz, "The role of tumor necrosis factor and interleukin6 in polycystic ovary syndrome," Polski Merkuriusz Lekarski, vol. 21, no. 125, pp. 489-491, 2006.

[62] S. Ceccarelli, N. Panera, M. Mina et al., "LPS-induced TNF- $\alpha$ factor mediates pro-inflammatory and pro-fibrogenic pattern in non-alcoholic fatty liver disease," Oncotarget, vol. 6, no. 39, pp. 41434-41452, 2015.

[63] J. S. Yudkin, C. D. A. Stehouwer, J. J. Emeis, and S. W. Coppack, "C-reactive protein in healthy subjects: associations with obesity, insulin resistance, and endothelial dysfunction: a potential role for cytokines originating from adipose tissue?" Arteriosclerosis, Thrombosis, and Vascular Biology, vol. 19, no. 4, pp. 972-978, 1999.

[64] J. S. Yudkin, M. Kumari, S. E. Humphries, and V. MohamedAli, "Inflammation, obesity, stress and coronary heart disease: is interleukin-6 the link?" Atherosclerosis, vol. 148, no. 2, pp. 209214, 2000.

[65] R. Anty, S. Bekri, N. Luciani et al., "The inflammatory C-reactive protein is increased in both liver and adipose tissue in severely obese patients independently from metabolic syndrome, type 2 diabetes, and NASH," The American Journal of Gastroenterology, vol. 101, no. 8, pp. 1824-1833, 2006.
[66] X. Wang, A. Ge, M. Cheng et al., "Increased hypothalamic inflammation associated with the susceptibility to obesity in rats exposed to high-fat diet," Experimental Diabetes Research, vol. 2012, Article ID 847246, 8 pages, 2012. 


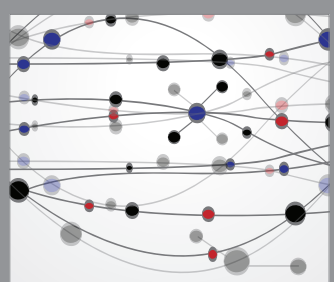

The Scientific World Journal
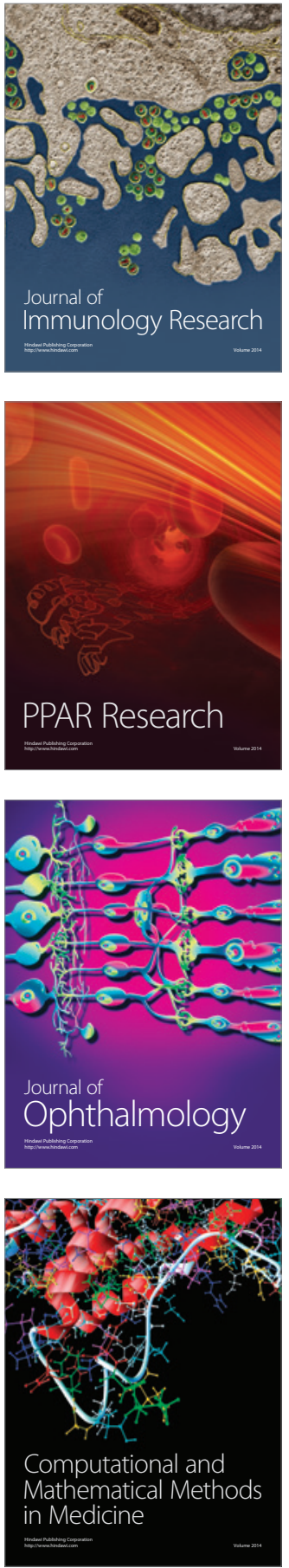

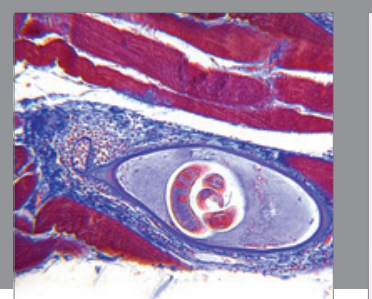

Gastroenterology Research and Practice

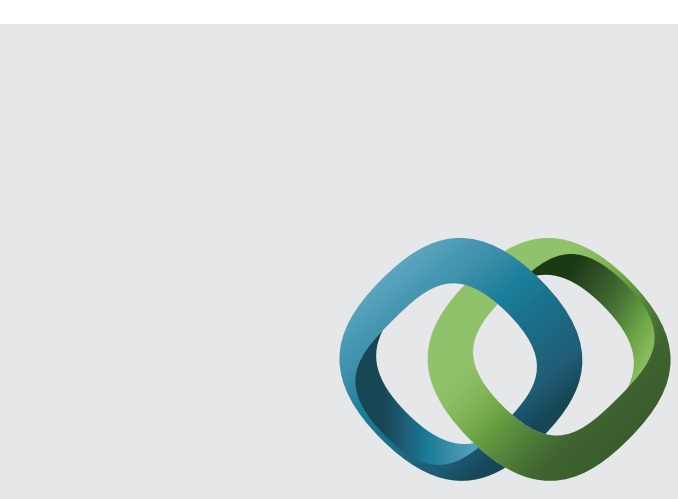

\section{Hindawi}

Submit your manuscripts at

http://www.hindawi.com
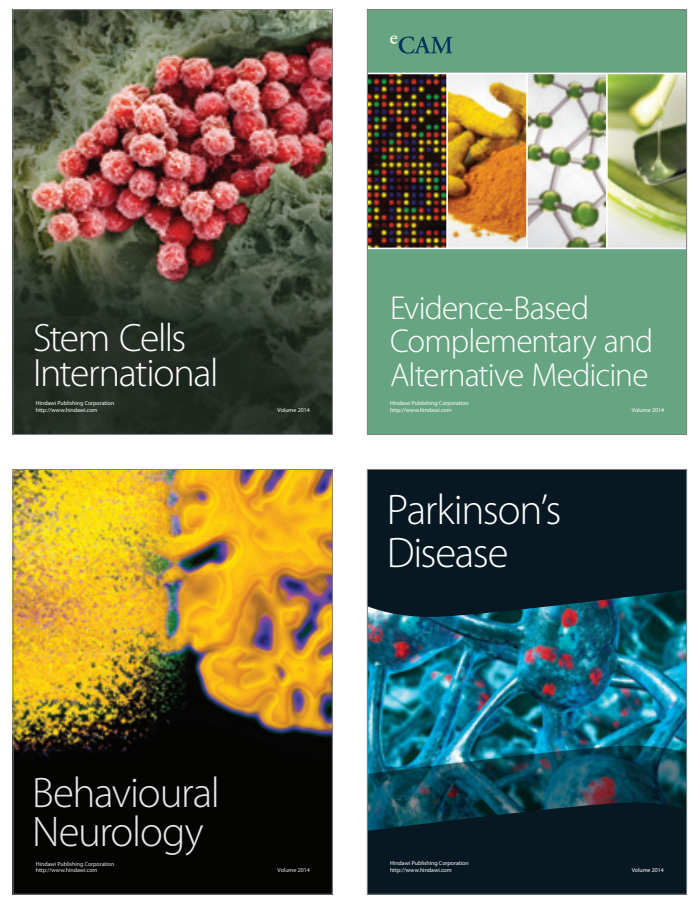
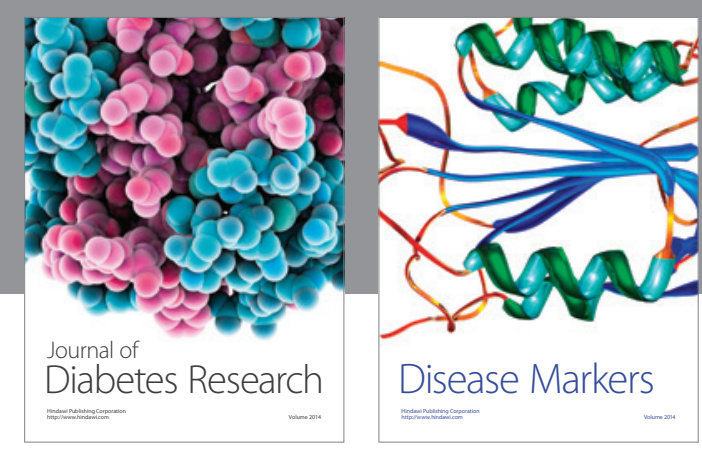

Disease Markers
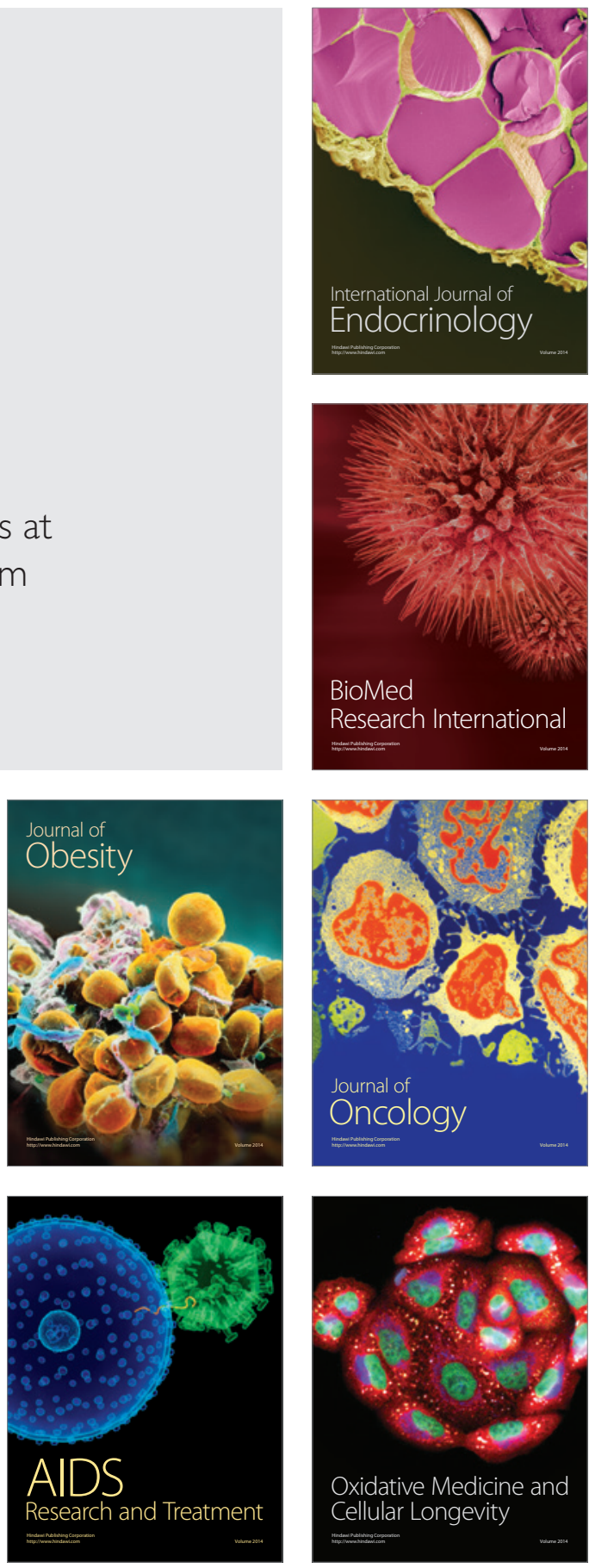